\title{
Hardware System of Mono Switch Resonant Inverter for Induction Heating
}

\author{
G.Mahesh $^{1}$, Dr. P. Sharath Kumar ${ }^{2}$, Dr. K. Ravi Kumar ${ }^{3}$ \\ ${ }^{1,3}$ Vasavi College of Engineering, Ibrahimbag, Hyderabad 500031, Telangana, India \\ ${ }^{2}$ CVR College of Engineering, Hyderabad, Telangana, India
}

\begin{abstract}
This paper presents a mono switch resonant DC - AC high-frequency converter for induction heating. In this, the inverter operated with variable switching frequency. Zero Voltage Switching frequency has been implemented to achieve higher efficiency. The converter output power can be controlled by the programmable PWM switching of the mono switch. The proposed method is more reliable for low power induction heating applications than the high power heating applications. The configuration of inverter is simulated in multi-sim environment and validated with experimental results. The experimental results are good agreement with simulation results.
\end{abstract}

Keywords: Mono switch resonant inverter, Induction heating, ZVS operation, Operational Amplifier (OPA), Touch Sense Input (TSI) and Programmable PWM

\section{Introduction}

Heat energy is essential for the human beings. There are several ways of obtaining this heat energy. The efficient and nonpolluting way of achieving the heat energy is through electrical power. Induction heating is the one of the electric heating among the conventional electrical heating methods. Induction heating has several applications such as induction cooking, metals heating, annealing, and hardening, etc. Induction heating requires high-frequency AC supply of 20 $\mathrm{kHz}$ to $400 \mathrm{kHz}$. The selection of frequency depends upon the type of application. Nowadays there have been lot developments in semiconductor technologies and converter configurations. It is enabling the use of power semiconductor devices such as MOSFETs and IGBTs for higher frequency level operations with lower power losses. In induction heating, eddy currents are generated in the load by highfrequency magnetic flux linkage with it based on Faraday's law of electromagnetic induction principle [1]. In the conventional electric heating methods, the heat transferred to the load by conduction or radiation. In induction heating, the temperature is raised directly inside the load due to the eddy currents. The depth of penetration of eddy currents is skin depth $(\delta)$ level in the load [2] given as follows

$$
\delta=\sqrt{ }\left(\rho / \mu \pi \mathrm{f}_{\mathrm{s}}\right)
$$

Where $\rho$ is electrical resistivity, $\mu$ is magnetic permeability of load material, and $f_{s}$ is the switching frequency of the converter circuit.

Generally Quasi-resonant inverter, half-bridge inverter, and full-bridge inverter topologies are used in induction heating applications. Out of these, the full-bridge inverter has become the favored topology due to the supply of peak to peak voltage across the load, which is the double that of the source voltage.

\section{Power Block diagram}

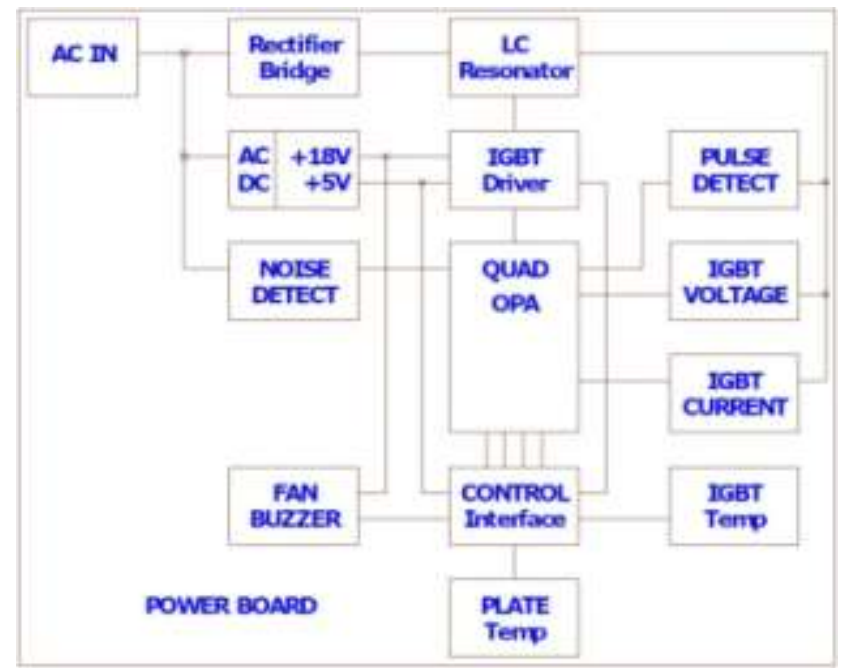

Figure 1: Power block diagram of Mono switch resonant converter

Fig. 1 shows the power block diagram. On the power circuit, the $\mathrm{AC}$ input is converted to around $+310 \mathrm{~V}$ by the bridge rectifier and regulated to $+18 \mathrm{~V}$ and $+5 \mathrm{~V}$ in the AC-DC module [8]. The LC resonator is powered from the $+310 \mathrm{~V}$ source to generate the magnetic field for heating. $+18 \mathrm{~V}$ is used to power the LC resonant IGBT driver circuit and the cooling fan. The $+5 \mathrm{~V}$ is the main supply for the whole system [8]. The Operation Amplifier is used to form the loop of pulse detection, noise detection, voltage and current measuring.

\section{Control Block diagram}

Volume 6 Issue 12, December 2017

www.ijsr.net

Licensed Under Creative Commons Attribution CC BY 


\title{
International Journal of Science and Research (IJSR) \\ ISSN (Online): 2319-7064
}

Index Copernicus Value (2016): 79.57 | Impact Factor (2015): 6.391

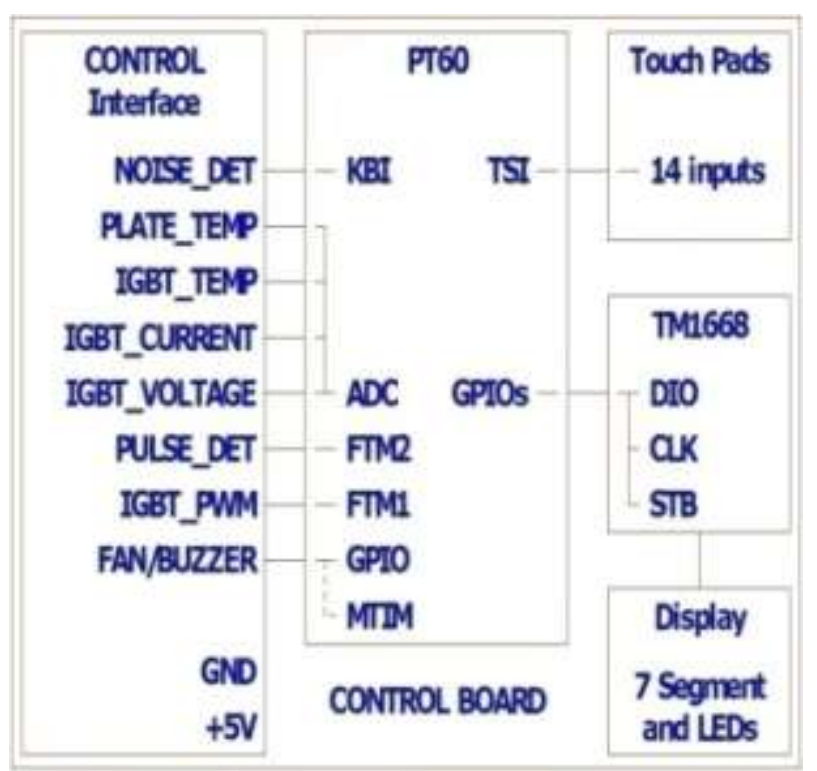

Figure 2: Control block diagram of Mono switch resonant inverter

Fig.2 Shows the Control block diagram of Mono switches resonant converter. The system is controlled entirely by a single 8-bit MCU on the control board with the following features [8]:

- Provides Touch Sense Input (TSI)

- Communicates with the display driver

- Drives the cooling fan and buzzer

- Outputs PWM to the IGBT driver

- Provides feedback from the power stage control

- Detects and measures: noise, temperature, voltage,

- and current

\subsection{Temperature sensing and V or I measurement}

Figure 3: Temperature sensing and voltage/current measurement as input to MCU.

For safety and protection, IGBT Temperature sensing, IGBT voltage, and IGBT current measurements are made as shown in Fig. 3. These measured values are input to the MCU internal Analog to Digital Converter.

RC filters are kept on the ADC inputs and placed close to the MCU which improve the EMC.

\subsection{IGBT driver with pulse detection}

Figure 4: IGBT driver and Pulse detection

The IGBT PWM signal is output from FTM1CH1[8], shown in Fig.4. Logical AND gate with Noise detection for noise protection used. The circuit converts the PWM signal from $5 \mathrm{~V}$ to $18 \mathrm{~V}$ so that the IGBT has driven appropriately.

\subsection{LC Parallel resonator}

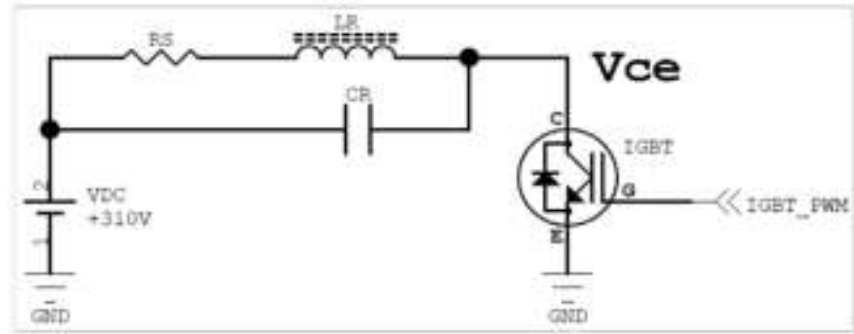

Figure 5: LC Parallel resonant equivalent circuit

A parallel LC Resonant circuit is shown in Fig. 5. As shown, the induction coil and the cookware form the equivalent Lr, and equivalent resistance Rs. This circuit resonated with resonant capacitor $\mathrm{Cr}$. Proper $\mathrm{Cr}$ should be selected so that the LC resonant frequency $(\mathrm{fr}=1 /(2 \pi \sqrt{ } \mathrm{LrCr})$ is higher than $20 \mathrm{KHz}$ to avoid audible frequency [8].

\section{Specifications and circuit Parameters}

Table 1: Specifications

\begin{tabular}{|c|c|c|}
\hline Component & Symbol & Rating \\
\hline AC input & $V s, f$ & $230 V, 50 H z$ \\
\hline Rectified Voltage & $\mathrm{V}_{\mathrm{dc}}$ & $310 \mathrm{~V}$ \\
\hline Load inductance & $\mathrm{L}_{\mathrm{r}}$ & $140 \mu \mathrm{H}$ \\
\hline Resonant Capacitor & $\mathrm{C}_{\mathrm{r}}$ & $0.3 \mu \mathrm{F}$ \\
\hline Resonant Frequency & $\mathrm{F}_{\mathrm{r}}$ & $24.56 \mathrm{kHz}$ \\
\hline
\end{tabular}

\section{Volume 6 Issue 12, December 2017}

\author{
www.ijsr.net
}


International Journal of Science and Research (IJSR)

ISSN (Online): 2319-7064

Index Copernicus Value (2016): 79.57 | Impact Factor (2015): 6.391

\begin{tabular}{|c|c|c|}
\hline $\begin{array}{c}\text { Operating switching } \\
\text { frequency range }\end{array}$ & $\mathrm{F}_{\mathrm{s}}$ & $\begin{array}{c}25 \mathrm{kHz} \text { to } \\
50 \mathrm{kHz}\end{array}$ \\
\hline IGBT & $20 \mathrm{~N} 120 \mathrm{R} 3$ & $1200 \mathrm{~V}, 20 \mathrm{~A}$ \\
\hline $\mathrm{MCU}$ & $S 08 P T$ & 8 -bit \\
\hline
\end{tabular}

\section{IGBT and Coil current Result waveforms}

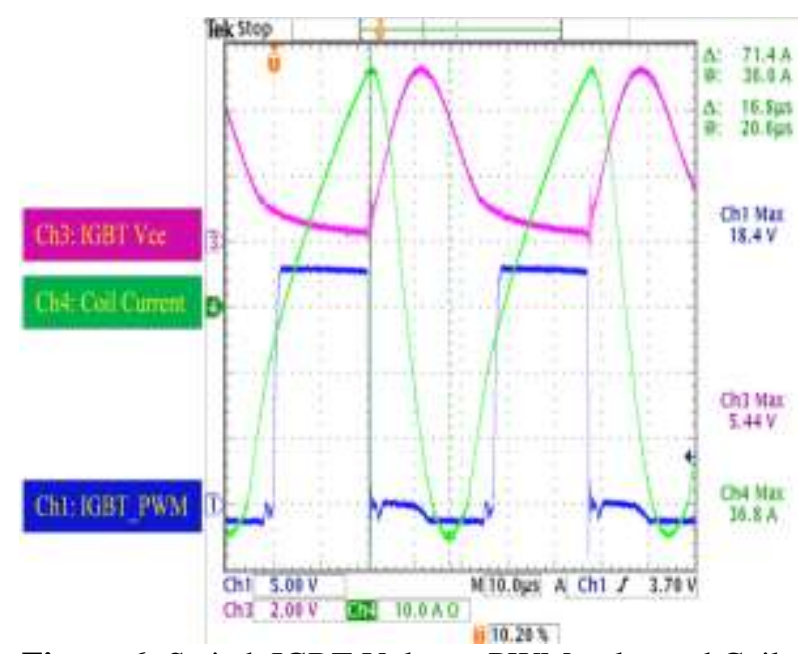

Figure 6: Switch IGBT Voltage, PWM pulse and Coil current

Fig.6 shows voltage across the mono switch Vce, switching gate pulse for load switching and the load current as coil current. The output power of the mono switch converter controlled by the pulse width of the switching gate pulse. The required PWM pulses obtained from the MCU depending upon the load requirement. The programme is loaded into the MCU for the switching pulse generation according to load requirement. The programming code not presented in this paper. When heating is in progress, the voltage of IGBT (Vce) will become higher and exceed the limit if the IGBT over drove or the load removed suddenly. Protection against this kind of situation also achieved by ADC ISR of the MCU. It stops the output of switching pulses to the IGBT driver circuit. The IGBT temperature and the load temperature are monitored continually for safety control.

\section{Experimental setup}

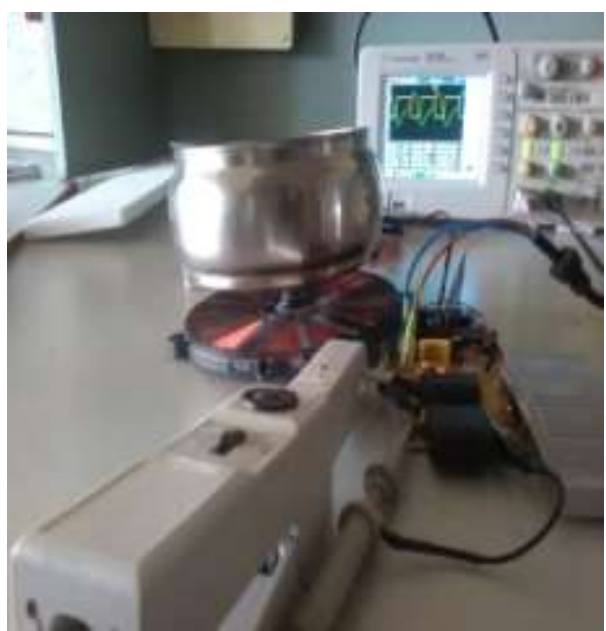

Figure 7: Experimental setup of Mono switch converter Circuit with the loaded vessel

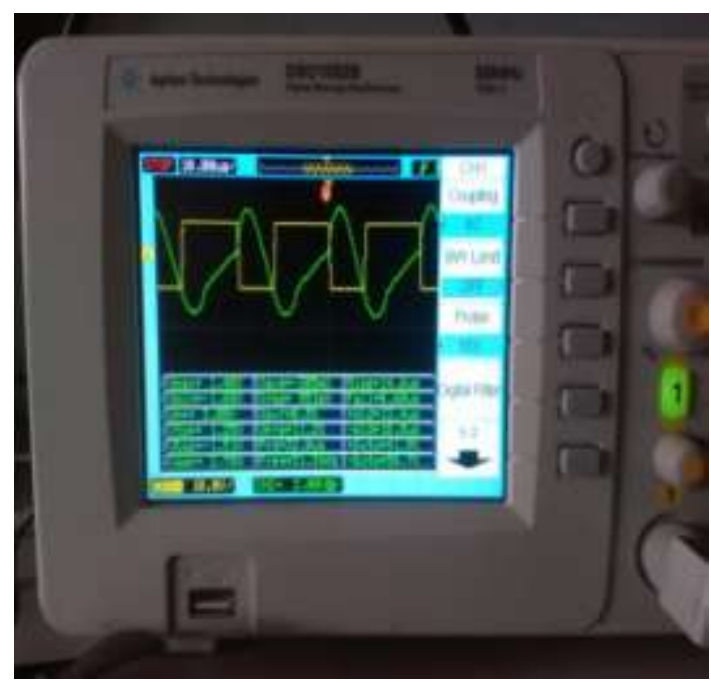

Figure 8: Experimental setup of Mono switch converter

Circuit Output Voltage and Current waveforms

Fig.7 shows the experimental setup of the proposed configuration. Fig.8 shows the inverter output voltage, and load current with ZVS. These experimental results are good agreement with simulation results.

\section{Conclusion}

In this paper, mono switch resonant High frequency inverter for induction heating has implemented. The proposed inverter configuration simulated in the multi-sim environment. Experimentally the inverter output power controlled using by programmable PWM of MCU for broad range control. The switching device is operated with ZVS. As the power handled by the inverter is small, and overall efficiency is not affected significantly. The simulation results are validated with the experimental results. The proposed configuration can be extended to multiple loads.

\section{References}

[1] W.C. Moreland, "The induction range: Its performance and its development problems", IEEE Trans. Ind. Appl., vol. IA-9, no. 1, Jan/Feb. 1973, pp.81-85

[2] Mokhtar Kamli, Shigehiro amamoto, Minoru Abe, “A $50-150 \mathrm{kHz}$ Half-Bridge Inverter for Induction Heating Applications", IEEE Trans. Industrial Electronics, vol. 43, no.1, February 1996 ,

[3] S.M.W. Ahmed, M. M. Eissa, M. Edress, T. S. AbdelHameed, "Experimental investigation of full bridge Series Resonant Inverters for Induction-Heating cooking appliances", $4^{\text {th }}$ IEEE Conference on Industrial Electronics and Applications, ICIEA 2009, Page(s): $3327-3332$.

[4] Atsushi Okuno, Hitoshi Kawano, Junming Sun, Manabu Kurokawa, Akira Kojina, Mutsuo Nakaoka, "Feasible Development of Soft - Switched SIT Inverter with Load - Adaptive Frequency-Tracking Control Scheme for Induction Heating", IEEE Trans. Industry Application, vol. 34, no. 4, 1998, pp.713-718.

[5] Young - Sup Kwon, Sang - Bong Yoo, Dong - Seok Hyun, "Half-Bridge series resonant Inverter for Induction Heating Applications with Load-Adaptive PFM Control Strategy", 14th Applied Power

Volume 6 Issue 12, December 2017 


\section{International Journal of Science and Research (IJSR) \\ ISSN (Online): 2319-7064}

Index Copernicus Value (2016): 79.57 | Impact Factor (2015): 6.391

Electronics Conference and Exposition, APEC'99.vol. 1, 1999, pp.575 - 581 .

[6] F. Forest, E. Laboure, F. Costa, J.Y. Gaspard, "Principle of a multi - load / single converter system for low power Induction Heating", IEEE Trans. Power Electronics, vol. 15, no. 2, 2000, pp.223 - 230.

[7] Jose M. Burdio, Fernando Monterde, Jose R. Garcia, Luis A. Barragan, Abelardo Martinez, "A Two Output Series - Resonant Inverter for Induction Heating Cooking Appliances", IEEE Trans. Power Electronics, vol. 20, Issue:4, 2005, pp.815 - 822.

[8] www.freescale.com

\section{Author Profile}

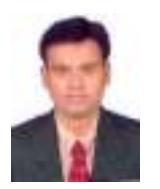

Mahesh G received the B.Tech. degree in Electrical \& Electronics Engineering from Jawaharlal Nehru Technological University Hyderabad in 2005 and M.Tech. degree in Power Electronics \& Industrial Drive from Jawaharlal Nehru Technological University Hyderabad in 2011. Since 2007, He has been working as Assistant Professor with the Electrical \& Electronics Engineering department, Vasavi College of Engineering, Hyderabad. His interests include power electronics, simulation, resonant inverters and solar charge controllers.

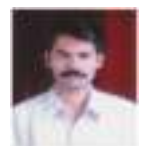

Sharath Kumar $\mathbf{P}$ received the B.Tech degree in Electrical \& Electronics Engineering from Jawaharlal Nehru Technological University Hyderabad in 2006, M.Tech degree in Power System from N.I.T Kurukshetra, Haryana in 2008 and Ph.D degree in Electrical Engineering from N.I.T Warangal, Telangana in 2016. Since 2007, $\mathrm{He}$ is currently working as Associate Professor with the Electrical \& Electronics Engineering department, CVR College of Engineering, Hyderabad. His research interests high frequency resonant inverters, induction heating applications, and distributed generation.

Ravi Kumar $\mathbf{K}$ received the B.Tech. degree in Electrical \& Electronics Engineering from Jawaharlal Nehru Technological University Hyderabad in 1998 and M.Tech. degree in Power Electronics from Jawaharlal Nehru Technological University Hyderabad in 2005. He obtained his $\mathrm{PhD}$ degree in Electrical Engineering from NIT Warangal under the guidance of Prof. M. Sydulu in 2016. Since 2001, He has been working as Associate Professor with the Electrical \& Electronics Engineering department, Vasavi College of Engineering, Hyderabad. His interests include power system optimization, AI applications to power systems, Economic operation of power systems, power quality, power system stability, contingency analysis, smart grid, renewable energy systems and power electronics.

Volume 6 Issue 12, December 2017 www.ijsr.net 